Casos Clínicos

Arch. Esp. Urol., 59, 7 (728-731), 2006

\section{LEIOMIOSARCOMA DE PENE: PRESENTACIÓN DE UN CASO Y REVISIÓN DE LA LITERATURA.}

Mauro Piana, Rodrigo Martínez Mansur, José Codone, Florencia Elizalde, Marcos Diez, Eduardo Reyes, Pablo Pipaón, Matias Villeta, Francisco Solano, Marcelo Lioy Lupis y Marcelo Amante.

Servicio de Urología. Hospital Dr. Cosme Argerich. Buenos Aires. Argentina. España.

Resumen.- OBJETIVO: El leiomiosarcoma primario de pene constituye una rara entidad. Desde 1930 hasta la actualidad han sido reportados solo 30 casos en la literatura mundial. Además de revisar las publicaciones disponibles al respecto desde 1957 hasta nuestros días, nosotros como objetivo quisimos añadir un nuevo caso a la literatura internacional sobre un paciente de 54 años con una lesión lobulada, de dos años de evolución a nivel del surco balanoprepucial, de $8 \times 4 \times 3 \mathrm{~cm}$., tratado con penectomía parcial inicialmente y penectomía total posterior a la misma. Analizamos evolución, progresión y tratamientos adyuvantes de esta infrecuente patología.

MÉTODOS/RESULTADOS: Presentamos un caso de un paciente masculino, detallamos la presentación clínica, los

Rodrigo Martínez Mansur

C/ Italia 1847 2ㅇ A

Rosario CP 2000

Santa Fe (Argentina)

drrmmmansur@yahoo.com

Trabajo recibido: 7 de septiembre 2005 exámenes complementarios utilizados para la estadificación, el tratamiento empleado y el control evolutivo.

CONCLUSIONES: El primer caso de leiomiosarcoma de pene fue descripto por Levi en 1930. Luego en 1957, Ashley y Edwards reportaron el primer caso en la literatura británica y en 1963, Pack refirió el primer caso en la literatura americana. Mc Kenzie y cols., fueron los primeros en reconocer dos tipos de leiomiosarcoma, los superficiales y los profundos. Los primeros se desarrollan desde células musculares lisas de estratos superficiales dérmicos glandelares y/o tercio distal peneano, son generalmente asintomático y de menor grado de malignidad, con escasa tendencia a invadir estructuras mas profundas, y con indemnidad uretral a la exploración. Los mejores predictores pronósticos serían el tipo tumoral a la presentación (superficial vs. profundo), y el tratamiento elegido para cada caso, donde la amputación total es más efectiva para tratamientos fracasados de resecciones locales que como tratamiento primario de los tumores profundos.

Palabras clave: Leiomiosarcoma de pene.

Summary.- OBJECTIVE: Primary penile leiomyosarcoma is a rare entity. Since 1930 only 30 cases have been reported in the bibliography. We wanted to add a new case to the international literature, in addition to a review of all available publications on the topic from 1957. A 54year-old patient presented with a lobulated $8 \times 4 \times 3 \mathrm{~cm}$ lesion in the balanopreputial groove over two years; he was treated initially with partial penectomy and subsequently with total penectomy. We analyze the evolution, progression and adjuvant treatments of this rare pathology.

METHODS/RESULTS: We report one case with its clinical presentation, diagnostic tests performed for staging, treatment and follow-up.

CONCLUSIONS: The first case of penile leiomyosarcoma was described by Levi in 1930. In 1957 Ashley and Edwards reported the first case in the British literature and in 1963 Pack reported the first in the American literature. Mackenzie et al. were the first to recognize two types of leiomyosarcoma: superficial and deep. The first develop from smooth muscle cells from the superficial dermal layers of the glans penis or distal third of the penis, they are generally asymptomatic and less malignant, rarely invading deeper structures and without involvement of the urethra on physical exam. The best prognostic predictors are type of tumor at presentation (superficial vs. deep) and treatment choice, being total penectomy more effective for failures of local resections than for primary treatment of deep tumors.

Keywords: Penile leiomyosarcoma. 


\section{INTRODUCCIÓN}

Los tumores de pene tienen una baja incidencia mundial, representando entre el $0,4 \%$ y $0,6 \%$ del total de las neoplasias malignas en EE.UU. y Europa, y el $10 \%$ en África y algunos países de América del Sur. De estos, los sarcomas de pene representan solo el $5 \%$ del total. Otros tumores malignos del tejido conectivo de pene incluyen al endotelioma (el más común), al rabdomiosarcoma y al sarcoma de Kaposi.

Clínicamente y anatomopatológicamente estos tumores se dividen en dos grupos, superficiales y profundos. En el caso de los superficiales, su crecimiento es lento, tienen tendencia a la recurrencia local pero con buen pronóstico tras su tratamiento con resección local con márgenes negativos como indicación inicial; en cambio los de carácter profundo son de patrón mas agresivo y de peor pronóstico, incluso tras procedimientos quirúrgicos radicales, potenciado por la indefinida y dudosa respuesta de estas neoplasias a la radioterapia y a la quimioterapia.

\section{CASO CLÍNICO}

Paciente de 54 años de edad, que consultó a nuestro Servicio en abril de 2005 por lesión de pene de 2 años de progresiva evolución.

Al examen físico se constató una masa de aspecto lobulado, a nivel del surco balanoprepucial, de $6 \times 2 \times 2 \mathrm{~cm}$ de diámetro, indolora, adherida a planos profundos con prepucio indemne., y sin evidencia de adenopatías inguinales bilaterales. No refirió trastornos miccionales.

Se efectuó biopsia de dicha formación bajo anestesia local que informó tumor fusocelular benigno. Se decide su exploración quirúrgica inmediata, realizándose tumorectomía peneana, por presunción de tumor tipo superficial y por su ubicación distal, con favorable evolución postoperatoria y externación (Figuras 1 y 2). El resultado anatomopatológico indicó tumor fusocelular maligno, con extensas áreas necróticas y hasta 16 mitosis atípicas, por 10 campos de gran aumento, que mide $8 \times 3 \times 2,5 \mathrm{~cm}$. Márgenes de resección en contacto con la lesión tumoral y prepucio sin particularidades.

Inmunohistoquimica: leiomiosarcoma de alto grado, con patrón histoarquitectural schwannoide; S100(-), Desmi$\mathrm{na}(++)$ y Actina muscular (+++) (Figuras 3 y 4$)$.

El paciente se reinternó quince días después, con tomografía de abdomen y pelvis con contraste endovenoso sin hallazgos patológicos y examen físico con signos persistencia tumoral, realizándose penectomía total con meato perineal.

El informe anatomo-patológico reveló pieza de pe-

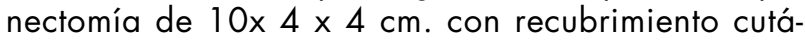
neo distal de $4 \mathrm{~cm}$. de longitud, tumor fusocelular maligno de alto grado compatible con leiomiosarcoma profundo con invasión de cuerpos cavernosos. Margen proximal, parenquimatoso y cutáneo: libre de lesión tumoral, no se observa invasión neural ni vascular con las técnicas de rutina (Figura 5).
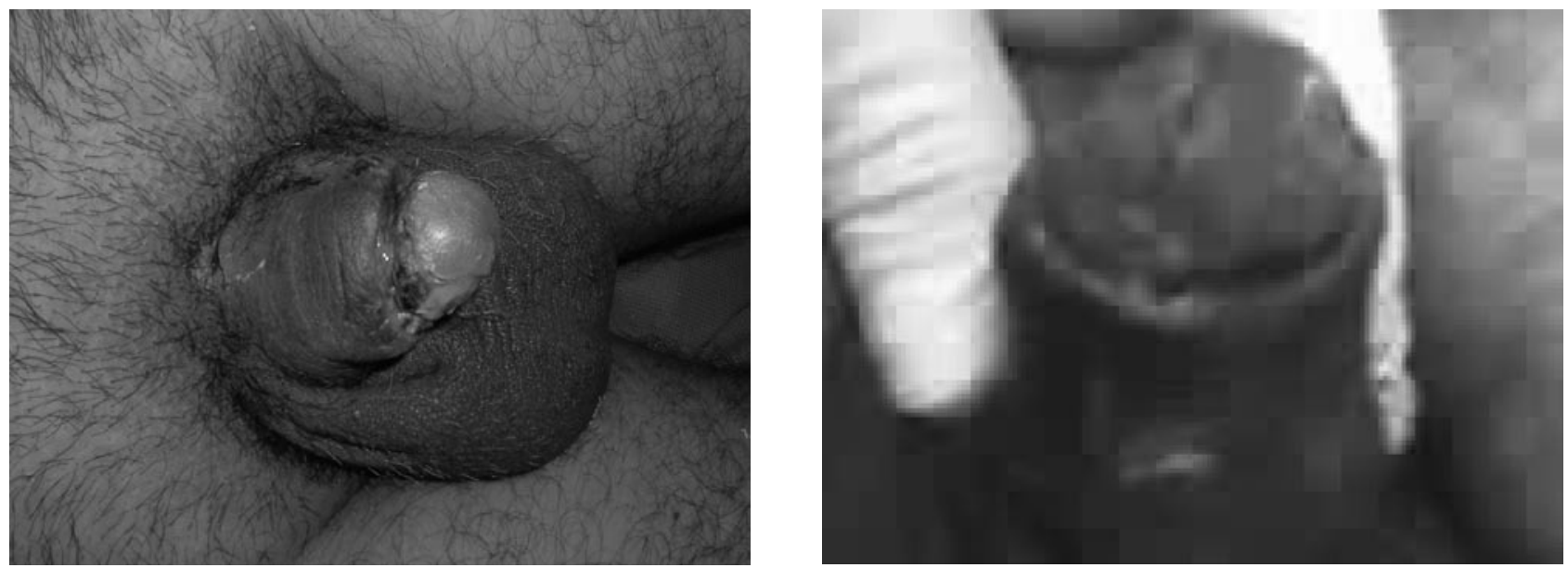

FIGURAS 1 y 2. Postoperatorio de penectomía parcial. 


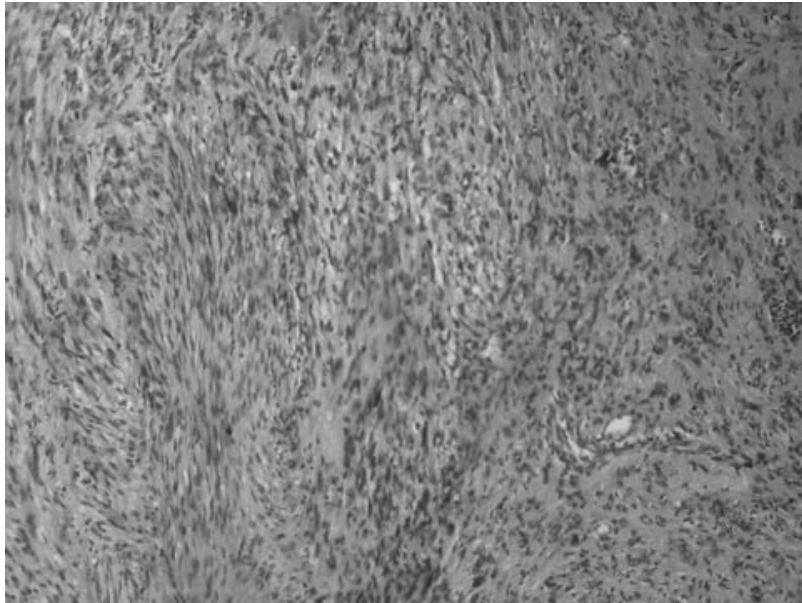

FIGURA 3. Proliferación fusocelular con sectores de atipía.

\section{Uretra libre de lesión}

Al cuarto día postoperatorio, evoluciona favorablemente, el paciente se externó con control por consultorios externos.

Actualmente el paciente permanece asintomático, bajo control urológico y oncológico sin realizar tratamiento adyuvante, asintomático y sin signos de recidiva local.

\section{Revisión Bibliográfica}

\section{DISCUSIÓN}

El primer caso de leiomiosarcoma de pene fue descripto por Levi en 1930. Luego en 1957, Ashley y Edwards reportaron el primer caso en la literatura británica y en 1963, Pack refirió el primer caso en la literatura americana. Posteriormente la casuística alcanzó los 30 casos hasta 2004. Las edades mas frecuentes de aparición van desde los 43 a 62 años, con un promedio de 51 años, con solo 3 casos presentados en niños. Las lesiones tienen desde $0,5 \mathrm{~cm}$ de diámetro hasta $11 \mathrm{~cm}$., y en la mayor parte de los casos son de aspecto lobulado, rosáceas o grisáceas, a veces ulceradas hasta sangrantes o necróticas. Además el inicio del tratamiento generalmente demoró un año o mas, en mas del $70 \%$ de los pacientes, debido a que habitualmente se los diagnosticó por biopsia.

Mc Kenzie y cols., fueron los primeros en reconocer dos tipos de leiomiosarcoma, los superficiales y los profundos. Los primeros se desarrollan desde células musculares lisas de estratos superficiales dérmicos glandelares

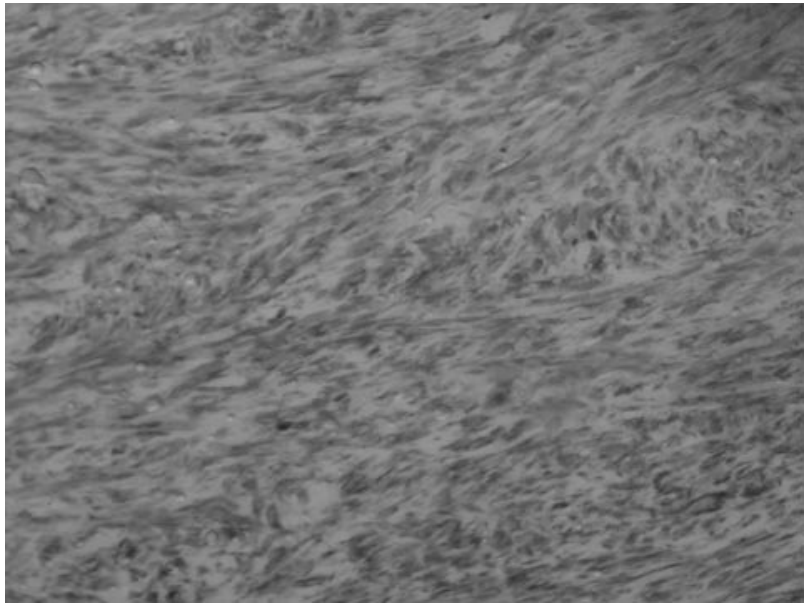

FIGURA 4. Desmina (+) para células neoplásicas.

y/o tercio distal peneano, son generalmente asintomático y de menor grado de malignidad, con escasa tendencia a invadir estructuras mas profundas, y con indemnidad uretral a la exploración. Debido a la alta tasa de recurrencia local tras la resección local tumoral (63\%), su tratamiento de elección lo constituiría la penectomía parcial con márgenes negativos de resección, según las diferentes publicaciones, disminuyendo dichas tasas. Respecto de los "profundos", se sostiene que se desarrollan desde células musculares lisas de cuerpos cavernosos y/o esponjoso, avanzando desde la base del pene hasta periné en la mayor parte de los casos reportados, con un comportamiento mas agresivo, mas tendientes a afectar la uretra y a producir síntomas. En estos casos la

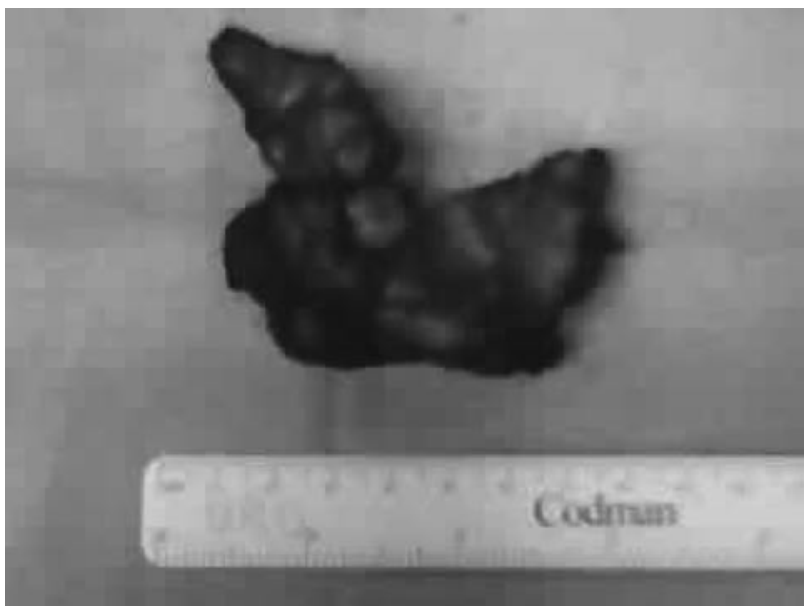

FIGURA 5. Pieza quirúrgica de tumorectomía. 
penectomía total con meato perineal fue el procedimiento elegido, pero el porcentaje de mortalidad a los dos años de la primera consulta continuó siendo elevado (promedio de 9 meses), con un 52\% de sobrevida.

Histológicamente predominaron los conglomerados celulares indefinidos de células lisas musculares, ahusadas, en fascículos entrelazados ( $90 \%$ de los casos), con importante actividad mitótica.

De la revisión de 30 casos de la literatura internacional, 19 casos fueron superficiales, permaneciendo todos vivos ante una media de seguimiento de 12 años, y de estos 19 pacientes, 5 mostraron recurrencia local entre los 3 y 18 meses de la resección primaria (26\%).

Los restantes 11 casos fueron profundos, falleciendo 8 pacientes entre 1 y 36 meses posteriores al diagnóstico $(73 \%)$, y 3 pacientes permanecieron vivos y libres de enfermedad a 6, 10, y 24 meses respectivamente, tras la cirugía radical $(27 \%)$.

El índice real de seguimiento solo está disponible en el $60 \%$ de los pacientes.

Las metástasis son raras al inicio de la presentación, incluso la presencia de linfadenopatías inguinales en los profundos es un evento tardío (contraindicando la linfadenectomía durante la penectomía total). Se demostró que la presencia de adenopatías es concomitante a la de metástasis, generalmente pulmonares (otros sitios de localización metastásica menos frecuentes son pericardio, riñón, estómago y ganglios).

Respecto de la aplicación de radioterapia o quimioterapia, no estaría indicada como tratamiento primario, y su papel como coadyuvantes pre o postoperatoria, no estaría del todo claro, y no existe en las diferentes publicaciones, una estadística segura que establezca que dichos procedimientos hacen decrecer el riesgo de recurrencia local o sistémica de la enfermedad.

Los mejores predictores pronósticos serían el tipo tumoral a la presentación (superficial vs. profundo), y el tratamiento elegido para cada caso, donde la amputación total es más efectiva para tratamientos fracasados de resecciones locales que como tratamiento primario de los tumores profundos.

\section{BIBLIOGRAFÍA y LECTURAS RECOMENDADAS (*lectura de interés $y^{* *}$ lectura fundamental)}

1. LEVI, I.: "Primary fibrosarcoma of the skin of the penis: Clinical and histologic study". Ital. Dermatol. Sifilol., 71: 1559, 1930.

2. ASHLEY, D.J.B.; EDWARDS, E.C.: "Sarcoma of the penis. Leiomyosarcoma of the penis: report of a case with review of the literature on sarcoma of the penis". Br. J. Surg., 45: 170, 1953.

3. PACK, G.; TRINIDAD, S.; HUMPHREYS, G.: "Primary leiomyosarcoma of the penis: a case report". J. Urol., 89: 839, 1963.

4. BAKKEN, C.L.; HANNA, E.A.; SEYBOLD, H.M.: "Leiomyosarcoma of the penis". J. Urol., 99: 769, 1968.

5. HUTCHESON, J.B.; WITTAKER, W.W.; FRONSTIN, M.H.: "Leiomyosarcoma of the penis: case report and review of the literature". J. Urol., 101: 874, 1969.

6. McKENZIE PRATT, R.; ROSS, R.: "Leiomyosarcoma of the penis: a report of a case". Br. J. Surg., 56: $870,1969$.

7. GREENWOOD, N.; FOX, H.; EDWARDS, E.C.: "Leiomyosarcoma of the penis". Cancer, 29: 481, 1972.

**8. HAMAL, P.B.: "Leiomyosarcoma of the penis: case report and review of the literature". Br. J. Urol., 47: 319, 1975.

9. McDONALD, M.; O’CONNELL, J.; MANING, J. y cols.: "Leiomyosarcoma of the penis". J. Urol., 130: 788, 1983.

10. ISSA, S.S.; ALMARAZ, R.; MAGOVERN, J.: "Leiomyosarcoma of the penis: case report and review of the literature". Cancer, 54: 939, 1984.

*11. SMART, R.: "Leiomyosarcoma of the penis". J. Urol., 356, 1984.

12. POW-SANG; ORIHUELA, E.: "Leiomyosarcoma of the penis". J. Urol., 151: 1643, 1994.

**13. FESTCH, J.; DAVIS, C.H.; MIETTINEN, M. y cols.: "Leiomyosarcoma of the penis. A Clinicopathologic Study of 14 cases with review of the literature and discussion of the differential diagnosis". Am. J. Surg. Pathol., 28: 115, 2004. 